\title{
EFFICIENCY OF USING \\ OFSET PRINTING MACHINE TO SPEED UP \\ MAGAZINE PRINT TIME
}

\section{EFISIENSI PENGGUNAAN MESIN CETAK OFSET UNTUK MEMPERCEPAT WAKTU CETAK MAJALAH}

\author{
Deden Nuryana $^{\mathrm{a}^{*}}$, A. Sarmada ${ }^{\mathrm{a}}$, Mukhyidin Djaiz ${ }^{\mathrm{a}}$, \\ a Teknik Grafika, Politeknik Negeri Media Kreatif, Indonesia \\ *Email: dedennuryana@gmail.com
}

\begin{abstract}
Optimization is an effort to maximize activities so that they are realized desired or desired advantage. Optimization in form Raw material planning can be defined as an activity which coordinated to achieve certain goals within a certain period of time. Raw material planning has an effect on operating costs, so that errors in inventory will reduce profits. Company Inventory problem, too much supply or even a shortage. Both of these conditions resulted in the emergence of this situation substantial costs. Therefore, it is necessary to plan the raw material inventory with the MRP method to analyze the optimal inventory level.

The purpose of planning and planning is to plan and controlling the flow of material into, inside, and out of the factory thus the position of optimal profit which is an attainable goal. Material requirements planning is carried out using the MRP method whose application begins with forecasting the number demand / production for the future. By seeing material requirements planning, then inventory planning is carried out by using the Horizontal Planning method. From the results of Horizontal Planning produce optimal inventory planning.
\end{abstract}

\section{Keywords: optimization, planning, MRP method.}

\begin{abstract}
Abstrak- Optimalisasi adalah usaha memaksimalkan kegiatan sehingga mewujudkan keuntungan yang diinginkan atau dikehendaki. Optimalisasi dalam bentuk perencanaan bahan baku dapat juga didefinisikan sebagai suatu kegiatan yang terkoordinasi untuk mencapai tujuan tertentu dalam kurun waktu tertentu. Perencanaan bahan baku berpengaruh terhadap besarnya biaya operasi, sehingga kesalahan dalam mengelola persediaan akan mengurangi keuntungan. Perusahaan seringkali mengalami masalah persediaan, diantaranya persediaan terlalu banyak
\end{abstract}


atau bahkan terjadi kekurangan. Kedua kondisi tersebut mengakibatkan timbulnya biaya yang besar. Oleh karena itu diperlukan perecanaan persediaan bahan baku dengan metode MRP untuk menganalisa tingkat persediaan yang optimum.

Tujuan dari perencanaan dan pengendalian produksi adalah merencanakan dan mengendalikan aliran material ke dalam, di dalam, dan keluar pabrik sehingga posisi keuntungan optimal yang merupakan tujuan perusahaan dapat dicapai. Perencanaan kebutuhan material dilakukan dengan menggunakan metode MRP yang penerapannya diawali dengan melakukan peramalan akan jumlah permintaan/produksi untuk waktu yang akan datang. Dengan mengetahui perencanaan kebutuhan material, kemudian dilakukan perencanaan persediaan dengan menggunkan metode Planning Horizontal. Dari hasil Planning Horizontal menghasilkan perencanaan persediaan yang optimal.

\section{Kata Kunci : Optimalisasi, perencanaan, metode MRP}

\section{PENDAHULUAN}

Proses industri dalam perusahaan Percetakan (perusahaan grafika) adalah perusahaan yang bergerak dalam bidang penjualan jasa cetakmencetak. Perusahaan Percetakan pada umumnya dapat dikategorikan dalam beberapa golongan, yaitu perusahaan kecil, perusahaan menengah, dan perusahaan besar. Proses industri harus dipandang sebagai suatu perbaikan terus-menerus (countinuous improvment), yang dimulai dari sederet siklus sejak adanya ide-ide untuk menghasilkan suatu produk, pengembagan produk, proses produksi, sampai distribusi kepada konsumen. Seterusnya, berdasarkan informasi sebagai umpanbalik yang dikumpulkan dari pengguna produk (pelanggan) itu kita dapat mengembangkan de-ide untuk menciptakan produk baru atau memperbaikan produk lama beserta proses produksi yang ada saat ini. (Vincent Gasperesz, 1998:1)

Dalam sistem manufaktur maupun non manufaktur, adanya persediaan merupakan faktor yang memicu peningkatan biaya. Meskipun demikian persediaan tetap diperlukan karena kondisi nyata dari permintaan dapat bersifat tidak pasti. Dalam mengadakan kegiatan produksi perusahaan dituntut untuk dapat memperediksi tingkat pasar, kapasitas produksi perusahaan, tempat dan biaya penyimpanan serta tenaga kerja yang diperlukan, sehingga mengefesienkan biaya produksi namun mengoptimalkan output produk. Untuk memenuhi hal itu perusahaan memerlukan sistem perencanaan 
produksi yang tepat. Dengan adanya erencanaan yang baik, maka biaya produksi akan lebih efektif serta permintaan pasar dapat terpantau. Oleh karena itu perencanaan produksi merupakan aspek penting yang harus diperhatikan perusahaan.

Memasuki era perdagangan bebas sekarang ini, perekonomian mengalami kemajuan yang sangat pesat dan persaingan sesama pelaku ekonomi juga semakin ketat. Kemampuan penyerapan dan pengguanaan teknologi dalam usaha meningkatkan kinerja perusahaan harus tetap ditingkatkan agar menghasilkan produk yang berkualitas bagus yang mampu bersaing di pasar. Pengelolaan proses produksi yang baik sangat dibutuhkan agar aktivitas produksi dapat berjalan dengan lancar, stabil, dan lebih baik untuk pencapain hasil yang optimal.

Persediaan merupakan hal pokok yang sangat penting dalam perusahaan. Bila perusahaan kekurangan persediaan bahannya (out of stock) akan mengakibatkan adanya hambatan-hambatan pada proses produksi, sehingga akan mengakibatkan kekurangan persediaan barang dagang dan dapat menimbulkan kekecewaan pelanggan. Selain pengelolaan persediaan yang menentukan berapa jumlah persediaan barang yang seharusnya ada, keseimbangan faktor produksi juga diperlukan untuk menunjang kelancaran aktivitas produksi.
Faktor produksi tersebut meliputi 5M yaitu material (bahan), machine (mesin), method (metode), money (uang/modal), dan man (sumber daya manusia). Kelima faktor produksi tersebut harus saling melengkapi dan tidak bisa bekerja sendiri-sendiri. Salah satu faktor yang menjadi bahan utama dalam proses produksi adalah material, yang membutuhkan pengelolaan yang baik agar tidak menghambat proses produksi. Oleh karena itu perencanaan kebutuhan bahan baku menjadi suatu hal yang sangat penting dan perlu diperhatikan karena proses produksi sangat bergantung pada ketersediaan bahan baku agar prosesnya tetap berjalan dengan lancar. Dalam hal ini perencanaan kebutuhan bahan baku harus diselaraskan dengan semua unsur perusahaan seperti modal yang tersedia, kondisi mesin produksi, keadaan sumber daya manusia, pesanan yang diterima, dan unsurunsur lainnya.

Bahan baku merupakan faktor utama bagi perusahaan untuk menunjang

kelancaran proses produski baik dalam perusahaan yang berkala besar ataupun

kecil. Penentuan persediaan bahan baku berbeda-beda untuk setiap perusahaan, baik untuk jumlah unit persediaan bahan baku yang ada dalam perusahaan, waktu penggunaan persediaan bahan baku, maupun jumlah biaya untuk membeli bahan baku tersebut. 
Berdasarkan permasalahan yang timbul ini penulis berinisiatif untuk menyusunan Penelitian tentang "Optimalisasi Perencanaan Penggunaan Bahan Baku Produksi Al-Quran dengan Menggunakan Metode MRP di PT. Sygma Exa Grafika”.

Penulis berharap agar tulisan ini dapat membantu untuk membuka pemahaman berbagai pihak akan pentingnya perencanaan tentang bahan baku kertas terhadap hasil proses produksi Al-Quran kareana perencanaan bahan baku kertas yang optmal akan membuat perencaan lebih efisien. Hal tersebut dapat dilakukan dengan menggunakan metode MRP (Material Requirement Planning) terhadap proses perencanaan penggunaan bahan baku kertas QPP (Quran Paper).

\section{METODE PENELITIAN}

Metode yang digunakan oleh penulis adalah metode kuantitatif. Metode penelitian kuantitatif merupakan salah satu jenis penelitian yang spesifikasinya adalah sistematis, terencana, dan terstruktur dengan jelas sejak awal hingga pembuatan desain penelitiannya. Definisi lain menyebutkan penelitian kuantitatif adalah penelitian yang banyak menuntut penggunaan angka, mulai dari pengumpulan data, penafsiran terhadap data tersebut, serta penampilan dari hasilnya.
Pada penelitian ini penulis menggunakan 3 teknik pengumpulan data yaitu Observasi, wawancara, dan studi pustaka.

\section{Observasi}

Merupakan kegiatan mengamati secara mendalam terhadap suatu objek yang menjadi perhatian utama penelitian di lapangan. Metode ini penulis gunakan untuk membuat perencanaan bahan baku kertas QPP (Quran Paper) mulai dari tahap awal produksi hingga akhir produksi.

\section{Wawancara}

Metode ini dilakukan dengan cara berdiskusi langsung dengan orang orang yang terkait dengan proses perencanaan bahan baku untuk melengkapi data data hasil pengamatan.

\section{Studi Pustaka}

Metode ini digunakan untuk menggali dasardasar teori dengan beberapa referensi buku yang dapat mendukung penjelasan pada hasil penelitian.

\section{Perencanaan Bahan Baku}

\section{Order Tetap}

Order tetap yang di produksi di PT. Sygma Exa Grafika adalah sebagian besar

AlQuran, ada beberapa nama order tetap pada tabel berikut ini:

Tabel 1. Order Tetap

\begin{tabular}{|c|c|c|}
\hline No & Order Tetap & \multicolumn{1}{|c|}{ Nama Judul } \\
\hline 1. & Al-Quran Wanita & Al-Quran Yasmina \\
\cline { 3 - 3 } & & Al-Quran Azalia \\
\hline
\end{tabular}




\begin{tabular}{|c|c|c|}
\hline 2. & $\begin{array}{l}\text { Al-Quran Kajian } \\
\text { Komperhensif }\end{array}$ & Al-Quran Fadhilah \\
\hline 3. & Al-Quran Anak & My First Al-Quran \\
\hline \multirow[t]{2}{*}{4.} & Al-Quran Tilawah & $\begin{array}{l}\text { Syaamil Quran } \\
\text { Cordova }\end{array}$ \\
\hline & & Syaamil Quran Mina \\
\hline 5 . & Al-Quran Terjemah Perkata & Syaamil Quran Hijaz \\
\hline 6. & Al-Quran Tajwid & $\begin{array}{l}\text { Syamil Quran } \\
\text { Bukhara }\end{array}$ \\
\hline 7. & Al-Quran Hafalan & Syamil Quran Tikrar \\
\hline \multirow[t]{3}{*}{8.} & Al-Quran Komperhensif & $\begin{array}{l}\text { Syamil Quran Miracle } \\
\text { The Practice }\end{array}$ \\
\hline & & $\begin{array}{l}\text { Syamil Quran Miracle } \\
\text { The Guidance }\end{array}$ \\
\hline & & $\begin{array}{l}\text { Syamil Quran Miracle } \\
\text { The Refference }\end{array}$ \\
\hline \multirow[t]{3}{*}{9.} & Buku Islam & $\begin{array}{l}\text { Muhammad } \\
\text { Teladanku }\end{array}$ \\
\hline & & 64 Sahabat \\
\hline & & 24 Nabi \\
\hline
\end{tabular}

(Sumber : PT. Sygma Exa Grafika, 2019)

\section{Order Tidak Tetap}

Untuk order tidak tetap yang di produksi di PT. Sygma Exa Grafika adalah buku-buku atau cetakan cetakan dari vendor luar.

\section{Proses Pengadaan Bahan Baku}

Dalam proses pengadaan bahan baku harus dilihat dari daftar kebutuhan dan membuat jadwal pengadaan bahan produksi.

\section{Daftar Kebutuhan}

Daftar kebutuhan untuk proses pengadaan yaitu terdiri dari kebutuhan bahan baku kertas dan bahan penolong dan chemical.

- Kebutuhan bahan baku kertas

Tabel 2. Kebutuhan Bahan Baku Kertas

\begin{tabular}{|c|c|c|c|}
\hline No & $\begin{array}{l}\text { Nama } \\
\text { Bahan }\end{array}$ & $\begin{array}{l}\text { Ukuran } \\
\text { Plano } \\
\text { (cm) }\end{array}$ & $\begin{array}{c}\text { Jlh } \\
\text { kertas / } \\
\text { rim }\end{array}$ \\
\hline 1. & QPP $50 \mathrm{gsm}$ & $61 \times 86 \mathrm{~cm}$ & $500 \mathrm{lbr}$ \\
\hline 2. & HVS $70 \mathrm{gsm}$ & $\begin{array}{l}61 \times 86 \mathrm{~cm} \\
65 \times 100 \mathrm{~cm} \\
79 \times 109 \mathrm{~cm}\end{array}$ & $500 \mathrm{lbr}$ \\
\hline 3. & HVS $80 \mathrm{gsm}$ & $\begin{array}{l}61 \times 86 \mathrm{~cm} \\
65 \times 100 \mathrm{~cm} \\
79 \times 109 \mathrm{~cm}\end{array}$ & $500 \mathrm{lbr}$ \\
\hline 4. & $\begin{array}{l}\text { HVS } 100 \\
\text { gsm }\end{array}$ & $\begin{array}{l}65 \times 100 \mathrm{~cm} \\
79 \times 109 \mathrm{~cm}\end{array}$ & $250 \mathrm{lbr}$ \\
\hline 5. & $\begin{array}{l}\text { Art Paper } 85 \\
\text { gsm }\end{array}$ & $\begin{array}{l}61 \times 92 \mathrm{~cm} \\
65 \times 100 \mathrm{~cm} \\
79 \times 109 \mathrm{~cm}\end{array}$ & $500 \mathrm{lbr}$ \\
\hline 6. & $\begin{array}{l}\text { Art Paper } \\
100 \text { gsm }\end{array}$ & $\begin{array}{l}61 \times 92 \mathrm{~cm} \\
65 \times 100 \mathrm{~cm} \\
79 \times 109 \mathrm{~cm}\end{array}$ & $250 \mathrm{lbr}$ \\
\hline 7. & $\begin{array}{l}\text { Art Paper } \\
120 \text { gsm }\end{array}$ & $\begin{array}{l}61 \times 92 \mathrm{~cm} \\
65 \times 100 \mathrm{~cm} \\
79 \times 109 \mathrm{~cm}\end{array}$ & $250 \mathrm{lbr}$ \\
\hline 8. & $\begin{array}{l}\text { Art Paper } \\
150 \mathrm{gsm}\end{array}$ & $\begin{array}{l}61 \times 92 \mathrm{~cm} \\
65 \times 100 \mathrm{~cm} \\
79 \times 109 \mathrm{~cm}\end{array}$ & $250 \mathrm{lbr}$ \\
\hline 9. & $\begin{array}{l}\text { Art Paper } \\
190 \text { gsm }\end{array}$ & $\begin{array}{l}61 \times 86 \mathrm{~cm} \\
65 \times 88 \mathrm{~cm} \\
79 \times 92 \mathrm{~cm}\end{array}$ & $\begin{array}{l}100 / 250 \\
\mathrm{lbr}\end{array}$ \\
\hline 10. & $\begin{array}{l}\text { Art Carton } \\
210 \mathrm{gsm}\end{array}$ & $61 \times 92 \mathrm{~cm}$ & $100 \mathrm{lbr}$ \\
\hline
\end{tabular}




\begin{tabular}{|c|l|l|l|}
\hline & & $\begin{array}{l}65 \times 100 \mathrm{~cm} \\
79 \times 109 \mathrm{~cm}\end{array}$ & \\
\hline 11. & $\begin{array}{l}\text { Art Carton } \\
230 \mathrm{gsm}\end{array}$ & $\begin{array}{l}61 \times 92 \mathrm{~cm} \\
65 \times 0 \mathrm{~cm} \\
79 \times 109 \mathrm{~cm}\end{array}$ & $100 \mathrm{lbr}$ \\
\hline 12. & $\begin{array}{l}\text { Art Carton } \\
260 \text { gsm }\end{array}$ & $\begin{array}{l}61 \times 92 \mathrm{~cm} \\
65 \times 100 \mathrm{~cm} \\
79 \times 109 \mathrm{~cm}\end{array}$ & $100 \mathrm{lbr}$ \\
\hline 13. & $\begin{array}{l}\text { Art Carton } \\
310 \text { gsm }\end{array}$ & $\begin{array}{l}65 \times 100 \mathrm{~cm} \\
79 \times 109 \mathrm{~cm}\end{array}$ & $100 \mathrm{lbr}$ \\
\hline 14. & $\begin{array}{l}\text { Art Carton } \\
400 \text { gsm }\end{array}$ & $\begin{array}{l}65 \times 100 \mathrm{~cm} \\
79 \times 109 \mathrm{~cm}\end{array}$ & $100 \mathrm{lbr}$ \\
\hline 15. & $\begin{array}{l}\text { Ivory } 210 \\
\text { gsm }\end{array}$ & $79 \times 109 \mathrm{~cm}$ & $100 \mathrm{lbr}$ \\
\hline 16. & $\begin{array}{l}\text { Ivory } 250 \\
\text { gsm }\end{array}$ & $79 \times 109 \mathrm{~cm}$ & $100 \mathrm{lbr}$ \\
\hline 17. & $\begin{array}{l}\text { Ivory } 300 \\
\text { gsm }\end{array}$ & $79 \times 109 \mathrm{~cm}$ & $100 \mathrm{lbr}$ \\
\hline 18. & $\begin{array}{l}\text { Ivory } 350 \\
\text { gsm }\end{array}$ & $79 \times 109 \mathrm{~cm}$ & $100 \mathrm{lbr}$ \\
\hline 19. & $\begin{array}{l}\text { BC Putih } \\
200 \text { gsm }\end{array}$ & $79 \times 109 \mathrm{~cm}$ & $100 \mathrm{lbr}$ \\
\hline 20. & $\begin{array}{l}\text { Samson } 75 \\
\text { gsm }\end{array}$ & $79 \times 109 \mathrm{~cm}$ & - \\
\hline 21. & $\begin{array}{l}\text { Ivory Food } \\
\text { grade } \\
215 \text { gsm }\end{array}$ & $79 \times 109 \mathrm{~cm}$ & $200 \mathrm{lbr}$ \\
\hline Sumber PT. & & \\
\hline
\end{tabular}

(Sumber : PT. Sygma Exa Grafika, 2019)

Keterangan :

- Art Carton 210 gsm untuk sheetblat buku mute

- Art Carton 260 gsm untuk sheetblat quran

- Ivory 350 gsm untuk lapisan cover jaket

- BC Putih 200 gsm untuk packing blanket mesin SM

- Samson 75 gsm untuk punggung buku mute, 64 sahabat, 24 nabi

- Ivory foodgrade 215 gsm untuk sheetblat quran

- Bahan Penolong Chemical

Tabel 3. Bahan Penolong dan Chemical

\begin{tabular}{|c|l|l|}
\hline No. & $\begin{array}{c}\text { Nama bahan } \\
\text { penolong } \\
\text { dan } \text { chemical }\end{array}$ & \multicolumn{1}{c|}{ Keterangan } \\
\hline 1. & Tinta New Graf & $\begin{array}{l}\text { - New Graf Black } \\
\text { - New Graf Magenta } \\
\text { - New Graf Cyan } \\
- \text { New Graf Yellow } \\
\text { - Master Black }\end{array}$ \\
\hline 2. & Lem & $\begin{array}{l}\text { - Adesin 8050 } \\
\text { - LA 240A } \\
\text { - Aquance GA 6660-E } \\
\text { - Jelly Glue }\end{array}$ \\
\hline 3. & Bahan Penolong & $\begin{array}{l}\text { - IPA Alkohol } \\
\text { - VWM Wash } \\
\text { - Fountain Supreme } \\
\text { - Plate cleanner } \\
\text { - Tinta Vernis } \\
\text { - Smash }\end{array}$ \\
\hline
\end{tabular}

(Sumber : PT. Sygma Exa Grafika, 2019)

\section{Jadwal Pengadaan}

Jadwal pengadaan bahan baku yang ada di PT. Sygma Exa Grafika adalah sebagai berikut:

- Cek output material gudang per hari

- Cek lead time vendor

- Kemampuan area gudang

Biasanya penjadwalan untuk pengadaan ada yang 3 hari, 1 minggu, 2 minggu dan 1 bulan.

\section{HASIL DAN PEMBAHASAN}

Penerapan Penggunaan Metode MRP (Material Requirement Planning) dalam Proses Perencanaan Bahan Baku Kertas QPP (Quran Paper) untuk Produksi Al-Quran

Dalam Penelitian penulis yang berjudul "Optimalisasi Perencanaan Penggunaan Bahan Baku Produksi Al-Quran 
dengan Menggunakan Metode MRP di PT. Sygma Exa Grafika". Agar lebih fokus dan terarah, maka dari itu penulis melakukan perencanaan bahan baku terhadap kertas QPP (Quran Paper) dengan metode MRP (Material Requirement Planning).

Mekanisme dari Proses MRP (Material Requirement Planning)

Dalam Mekanisme dari proses MRP (Material Requirement

Planning) menggunkan planning horizon yaitu merupakan banyaknya waktu ke depan (masa mendatang) yang tercakup dalam perencanaan. Dalam praktek, planning horizon harus ditetapkan paling sedikit sepanjang waktu kumulatif dari sekumpulan item yang terlibat dalam proses perencaan bahan baku kertas QPP (Quran Paper). Sebelum membuat mekanisme dari proses MRP (Material Requirement Planning) ada beberapa yang harus diketahui sebagai berikut :

1. Menghitung Berat Kertas per Lembar

Rumus :

Panjang x Lebar x Gramatur

$$
100 \times 100
$$

Diketahui Kertas QPP 50 gram/m2, ukuran 61 $\mathrm{x} 86 \mathrm{~cm}$.

$$
\begin{aligned}
& =\frac{61 \times 86 \times 50}{100 \times 100}(\mathrm{gram}) \\
& =26,23 \mathrm{gram} / \mathrm{lembar}
\end{aligned}
$$

2. Menghitung Berat Kertas Satu Rim Plano Rumus :

Panjang x Lebar x Gramatur x 500

$$
100 \times 100 \times 1000
$$

Diketahui Kertas QPP 50 gram/m2, ukuran 61 x $86 \mathrm{~cm}$. Satu rim sama dengan

500 lembar.

$$
=\frac{61 \times 86 \times 50 \times 500}{100 \times 100 \times 1000}=13,115 \mathrm{kilogram} / \mathrm{rim}
$$

Jika satu kertas QPP 50 gram/m2 dari ukuran 61 x $86 \mathrm{~cm}$ beratnya adalah 26,23 gram/lembar dan berat kertas dari satu rim plano 13,115 kilogram/rim. Maka jika setiap tiga minggunya pengadaan untuk kertas QPP itu 5 ton / 5000 kilogram terdapat 382 rim palno kertas QPP ukuran 61 x $86 \mathrm{~cm}$.

\section{Planning Horizon}

Tabel 4. Planning Horizon MRP

\begin{tabular}{|l|c|c|c|c|c|}
\hline \multicolumn{5}{|c|}{$\begin{array}{l}\text { Lot Size : 5000 kg } \\
\text { Safety Stock : 0 }\end{array}$} \\
\hline $\begin{array}{l}\text { Lead Time : 3 } \\
\text { weeks }\end{array}$ & \multicolumn{5}{|c|}{ Time Periods (Weeks) } \\
\hline $\begin{array}{l}\text { On Hand : 2000 } \\
\text { kg }\end{array}$ & 1 & 2 & 3 & 4 & 5 \\
\hline $\begin{array}{l}\text { Gross } \\
\text { Requirements }\end{array}$ & 1300 & 1500 & 1400 & 1400 & 1500 \\
\hline $\begin{array}{l}\text { Scheduled } \\
\text { receipts }\end{array}$ & & 5000 & & & \\
\hline $\begin{array}{l}\text { Projected On- } \\
\text { Hand }\end{array}$ & 700 & 4200 & 2800 & 1400 & -100 \\
\hline $\begin{array}{l}\text { Projected } \\
\text { Availabel }\end{array}$ & & & & & 4900 \\
\hline $\begin{array}{l}\text { Net } \\
\text { Requirements }\end{array}$ & & & & & 100 \\
\hline $\begin{array}{l}\text { Planned Order } \\
\text { Receipts }\end{array}$ & & & & & 5000 \\
\hline $\begin{array}{l}\text { Planned Order } \\
\text { Release }\end{array}$ & & 5000 & & & \\
\hline
\end{tabular}


Keterangan :

- Lead Time merupakan jangka waktu yang dibutuhkan sejak MRP menyarankan suatu pesanan sampai item yang dipesan itu siap untuk digunakan. Dikethui bahwa waktu tunggu (lead time) adalah 3 minggu.

- On Hand untuk menunjukan kuantitas dari item yang secara fisik ada dalam stockroom. Diketahui bahwa inentori onhand adalah $2000 \mathrm{~kg}$.

- Lot Size merupakan kuantitas pesanan (order quantity) dari item yang memberitahukan MRP berapa banyak kuantitas yang harus dipesan. Ukuran kuantitas pesanan adalah tetap sebesar 5000 kg kertas QPP (Quran Paper)

- Safety Stock merupakan stock pengaman yang ditetapkan oleh perencana MRP untuk mengatasi fluktuasi dalam permintaan (demand) dan/atau penawaran (supply). Dalam kasus ini stok pengaman diasumsikan nol.

- Planning Horizon merupakan banyaknya waktu ke depan (masa mendatang) yang tercakup dalam perencanaan. Planning horizon dalam tabel diatas adalah 5 minggu.

- Gross Requirements (kebutuhan kotor) merupakan total dari semua kebutuhan, termasuk kebutuhan yang diantisipasi, (anticipated requirements), untuk setiap periode waktu. Proses produksi Al-Quran yang menggunakan bahan baku kertas QPP (Quran Paper). Diketahui bahwa kenutuhan kotor (Gross Requirements) untuk periode satu adalah $1300 \mathrm{~kg}$, periode dua adalah $1500 \mathrm{~kg}$, periode tiga adalah $1400 \mathrm{~kg}$, periode empat $1400 \mathrm{~kg}$, periode lima $1500 \mathrm{~kg}$.

- Scheduled Receipts merupakan jadwal penerimaan. Diketahui jadwal penerimaan bahan baku kertas QPP (Quran Paper) adalah di periode dua.

- Projected On-Hand merupakan projected avaliable balance (PAB) dan tidak termasuk planned orders. Projected OnHand dihitung berdasarkan formula:

Projected On-Hand: On-Hand pada awal periode + Scheduled Receipts-Gross Requirements

Diketahui bahwa on-hand pada awal periode satu adalah $1000 \mathrm{~kg}$, sehingga projected on-hand untuk periode satu, dua, tiga, empat dan lima dihitung sebagai berikut:

Projected on-hand periode 1

$=2000+0-1300=700 \mathrm{~kg}$

Projected on-hand periode 2

$=700+5000-1500=4200 \mathrm{~kg}$

Projected on-hand periode 3

$=4200+0-1400=2800 \mathrm{~kg}$

Projected on-hand periode 4

$=2800+0-1400=1400 \mathrm{~kg}$

Projected on-hand periode 5 
$=1400+0-1500=-100 \mathrm{~kg}$

- Projected Available merupakan kuantitas yang diharapkan ada dalam inventory pada tahap akhir, dan tersedia untuk pengguna dalam periode selanjutnya. Projected available dihitung berdasarkan formula berikut :

Projected Available = On-Hand pada awal periode (atau Project Available periode sebelumnya) + Scheduled Receipts perode sekarang + Planned Order Receipts periode sekarang - Gross Requirements periode sekarang

Dalam projected available dihitung sebagai berikut:

Projected available pada akhir periode 1 $=2000+0+0-1300=700 \mathrm{~kg}$

Projected available pada akhir periode 2 $=700+5000+0-1500=4200 \mathrm{~kg}$

Projected available pada akhir periode 3 $=4200+0+0-1400=2800 \mathrm{~kg}$ Projected available pada akhir periode 4 $=2800+0+0-1400=1400 \mathrm{~kg}$ Projected available pada akhir periode 5 $=1400+0+5000-1500=4900 \mathrm{~kg}$

Net Requirements, merupakan kekurangan material yang diproyeksikan untuk periode ini, sehingga perlu diambil tindakan ke dalam perhitungan planned order receipts agar menutupi kekurangan material pada periode itu. Net Requirements dihitung berdasarkan formula berikut :

Net Requirements

$=$ Gross Requirement + Allocatons + Safety Stock -Scheduled Receipts - Projected Available pada akhir periode lalu Berdasarkan formula di atas, net requirement dapat dihitung untuk periode lima, sebagai berikut :

Net Requirements pada periode 5

$=1500+0+0-1400=100 \mathrm{~kg}$

- Planned Order Receipts merupakan kuantitas pesanan pengisian kembali yang telah direncanakan oleh MRP untuk diterima pada periode tertentu guna memenuhi kebutuhan bersih (net requirements).

- Planned Order Release merupakan kuantitas yang ditempatkan atau dikeluarkan dalm periode tertentu, agar item yang dipesan itu akan tersedia pada saat dibutuhkan.

Proses MRP merupakan suatu kombinasi dari empat proses logik yang sangat sederhana, yaitu:

(1) penentuan net requirement untuk setiap periode

(2) penentuan planned orders untuk setiap periode,

(3) leadtime offsetting,dan

(4) expolding planned orders. 
Optimalisasi Perencanaan Penggunaan Bahan Baku Kertas QPP (Quran Paper) untuk Produksi Al-Quran

Dalam proses produksi untuk mencapai optimalisasi, banyak hal yang harus diperhatikan terutama dalam menyusun rencana produksi karena akan menjadi landasan dalam melakukan produksi. Optimalisasi proses produksi merupakan cara untuk memaksimalkan hasil produksi (output).

\section{Perencanaan Proses Pengadaan Bahan}

\section{Baku Kertas QPP (Quran Paper)}

Perencanaan proses pengadaan bahan baku kertas QPP (Quran Paper) Pertama yaitu menentukan apakah yang menjadi keluaran dan seberapa besar kebutuhan akan produk yang akan dihasilkan. Setelah tahap ini kemudian menentukan rencana produksi di dalam perusahaan. Rencana ini menghasilkan informasi yang penting untuk menentukan bahan baku kertas QPP (Quran Paper). Akibatnya, keberhasian tiap tahap ditentukan oleh tahap sebelumnya.

Dalam proses perencanaan pengadaan bahan baku kertas QPP (Quran

Paper) agar lebih optimal dalam pelaksanaanya yaitu sebagai berikut:

1. Kebutuhan material dihitung dalam metode MRP (Material Requirement

Planning).
2. Kuantitas yang tersedia berdasrkan pada balances on-hand, dengan mempertimbangkan kuantitas yang dialokasikan untuk kebutuhan spesifik.

3. Tentukan lead time waktu pengadaan kertas QPP (Quran Paper).

4. Tentukan waktu periode pengadaan bahan baku kertas QPP (Quran Paper).

5. Tentukan penempatan untuk proses penyimpanan kertas QPP (Quran Paper) dan layout tataletak penyimpanannya dengan sebaik mungkin

6. Tentukan kapan waktu untuk pengeluaran bahan baku kertas QPP (Quran Paper).

\section{Proses Bahan Baku Kertas QPP (Quran} Paper) untuk Produksi Al-Quran Agar Optimal.

Barang dalam proses (material in process), yaitu barang/bahan yang belum selesai dalam proses produksi. Bahan tersebut menunggu dalam antrian unuk diproses lebih lanjut. Agar lebih optimal untuk proses produksi perlu adanya Pengendalian produksi. Rangkaian prosedur yang diarahkan pada semua elemen dalam proses produksi, antara lain pengendalian bahan, harga beli bahan baku, proses produksi, standar kualitas produksi, tenaga kerja dan sebagainya sehingga memberikan hasil dengan ongkos terendah dalam waktu tercepat. Dalam pengendalian produksi harus 
mempertimbangkan kondisi saat ini dan masa yang akan datang.

Agar aktivitas proses produksi bahan baku kertas QPP (Quran Paper) untuk prduksi Al-Quran lebih optimal, harus dibuat tujuan utuma untuk pengendalian produksi dan bahan baku kertas QPP (Quran Paper), pemaparanya sebagai sebagai berikut:

1. Memaksimumkan Tingkat Pelayanan Pelanggan Dalam memaksimumkan tingkat pelayanan pelanggan dimana sasaran untuk tingkat pelayanan (service levels) harus ditetapkan dan performansi diukur untuk menjamin bahwa pelayanan telah diberikan secara tepat. Beberapa elemen yang penting dalam hal ini adalah:

- Kualitas Produk

- Ketersediaan produk apabila diinginkan atau dijanjikan

- Harga yang kompetitif

- Tingkat pengisisan stok produk akhir untuk membuat stok (make-tostock) dan Penyerahan tepat waktu untuk membuat sesuai pesanan (make-to-order)

Pelayanan pelanggan dalam konteks ini mencangkup pelanggan eksternal (external customer) yang membeli produk dan pelanggan internal (internal customer) seperti : departemen pembelian, departemen pemasaran, dan lain-lain melalui menyerahkan produk-produk berkualitas / produk Al-Quran tepat waktu.
2. Meminimumkan investasi inventori Dalam pengendalian yang baik akan mencapai aliran produksi yang mulus dengan inventori minimum dalam pabrik/perusahaan dan waktu tunggu yang pendek (short lead times). Pengendalian yang jelek dari aktivitas produksi akan membutuhkan tambahan investasi dalam inventori bahan baku (raw material) terutama bahan baku kertas karena bahan baku kertas yang paling dominan dalam sebuah produksi cetak, dan produk akhir (finished goods) guna mengatasi kelemahan dalam perencanaan dan pelaksanaan produksi, dengan mempertimbangkan dampak dari: kekurangan bahan baku kertas QPP (Quran Paper), kualitas yang tidak menentu, tanggal tengat yang terlewat (missed due dates), pemeliharaan mesin dan peralatan yang jelek.

\section{Efesiensi Operasi}

Ongkos-ongkos inventori harus diminimumkan guna memperoleh harga yang kompetitif. Pengendalian ongkos-ongkos membutuhkan operasi yang efesien dari keseluruhan organisasi. Elemen-elemen yang perlu diperhatikan dalam efesiensi operasi, adalah: supervisi pabrik dan tenaga kerja tidak langsung, dukungan dan keterlibatan pekerja, mesin dan peralatan yang andal, fasilitas pendukung yang efektif, dan lain-lain. Situasi pengendalian aktivitas produksi, baik atau jelek, akan mempengaruhi 
secara langsung terhadap pelayanan pelanggan, investasi inventori, dan efesiensi penggunaan bahan baku kertas QPP (Quran Paper).

Pada dasarnya fungsi dasar yang harus dipenuhi oleh aktivitas perencaan dan pengendalian produksi adalah:

1. Meramalkan permintaan produk yang dinyatkan dalam jumlah produk sebagai fungsi dari waktu;

2. Menetapkan jumlah dan saat pemesanan bahan baku serta komponen secara okonomis dan terpadu.

3. Menetapkan keseimbangan antara tingkat kebutuhan produksi, teknik pemenuhan pesanan, serta memonitor tingkat persediaan produk setiap saat, membandingkannya dengan rencana persediaan, dan melakukan revisi atas rencana produksi pada saat yang ditentukan; serta

4. Membuat jadwal produksi, penugasan, pembebanan mesin dan tenaga kerja yang terperinci sesuai dengan ketersediaan kapasitas dan fluktuasi permintaan pada suatu periode.

\section{Proses Distribusi}

Distribusi dari barang mengacu pada hubungan yang ada di antara titik produksi dan pelanggan akhir, yang sering terdiri dari beberapa inventori yang harus dikelola. Agar sesuai dengan tujuan yang ada yaitu memperoleh inventori dalam tempat yang tepat, pada waktu yang tepat, spesifikasi kualitas yang tepat, serta ongkos yang memadai. Keputusankeputusan distribusi akan mempengaruhi :

1. Fasilitas

2. Transfortasi

3. Investasi inventori

4. Frekuensi kehabisan stok (stockout)

5. Komunikasi dan pemrosesan data Dengan stok barang yang cukup fasilitas semua memadai, maka akan membantu memaksimalkan proses distribusi dan meningkatkan income perusahaan. Selain itu konsumen juga akan merasa lebih nyaman karena produk yang dibutuhkan bisa terpenuhi.

Kelebihan dan Kekurangan Penerapan Perencanaan Penggunaan Bahan Baku Kertas QPP (Quran Paper) dengan menggunakan Metode MRP (Material Requirement Planning)

Dalam perencanaan bahan baku terhadap kertas QPP (Quran Paper) dengan metode MRP (Material Requirement Planning), terdapat beberapa kelebihan dan kekurangan dalam menggunkan metode MRP (Material Requirement Planning) tersebut untuk perencanaan bahan baku kertas QPP (Quran Paper). 


\section{Kelebihan Perencanaan Penggunaan}

Bahan Baku Menggunkaan Metode MRP

1) Kemampuan memberi harga lebih kompetitif;

2) Mengurangi harga penjualan;

3) Mengurangi Inventori;

4) Pelayanan pelanggan yang lebih baik;

5) Respon terhadap permintaan pasar lebih baik;

6) Kemampuan mengubah jadwal induk;

7) Menunda atau membatalkan pesanan;

8) Mengubah kuantitas pesanan;

9) Memajukan atau menunda batas waktu pesanan.

Kekurangan Perencanaan Penggunaan

\section{Bahan Baku Menggunkan Metode MRP}

1) Penggunaan sistem MRP adalah integritas data. Jika terdapat data salah pada data persediaan, bill material data/master schedule kemudian juga akan menghasilkan data salah;

2) MRP sistem membutuhkan data spesifik berapa lama perusahaan menggunakan berbagai komponen dalam memproduksi produk tertentu (asumsi semua variable);

3) Sistem ini juga mengasumsikan bahwa "lead time" dalam proses in manufacturing sama untuk setiap item produk yang dibuat.
KESIMPULAN

Penerapan Penggunaan Metode MRP (Material Requirement Planning) dalam Proses Perencanaan Bahan Baku Kertas QPP (Quran Paper) untuk Produksi AlQuran

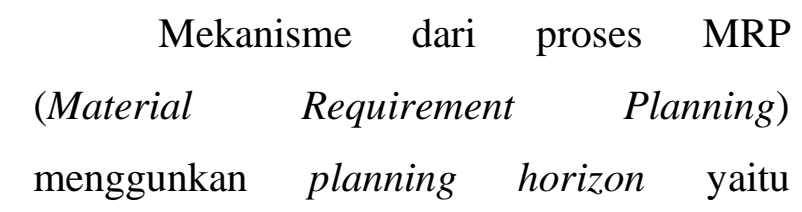
merupakan banyaknya waktu ke depan (masa mendatang) yang tercakup dalam perencanaan. Dalam praktek, planning horizon harus ditetapkan paling sedikit sepanjang waktu kumulatif dari sekumpulan item yang terlibat dalam proses perencaan bahan baku kertas QPP (Quran Paper). Ada bebrapa mekanisme untuk Planning horizon yaitu: Lead Time, On Hand, Lot Size, Safety Stock, Gross Requirement, Scheduled Receipts, Projected On-Hand, Projected Available, Net Requirments, Planned Order Receipts, Planned Order Release. Untuk proses pelaksanaan masih dengan metode manual.

\section{Optimalisasi Perencanaan Penggunaan} Bahan Baku Kertas QPP (Quran Paper) untuk Produksi Al-Quran

Optimalisasi proses produksi merupakan cara untuk memaksimalkan hasil produksi (output). Optimalisasi proses produksi ini terdapat beberapa komponen 
yaitu : Perencanaan proses pengadaan bahan baku kertas QPP (Quran Paper), aktivitas proses bahan baku kertas QPP (Quran Paper) untuk produksi Al-Quran agar optimal dan Proses Distribusi. Dalam pelaksananya di lapangan untuk mencapai hasil yang optimal masih harus banyak perbaikan dari perencanaan bahan baku untuk kertas QPP (Quran Paper).

\section{Kelebihan dan Kekurangan Penerapan} Perencanaan Penggunaan Bahan Baku Kertas QPP (Quran Paper) dengan menggunakan Metode MRP (Material Requirement Planning)

Terdapat beberapa kelebihan dan kekurangan dalam penerapan metode MRP (Material Requirement Planning) tersebut untuk perencanaan bahan baku kertas QPP (Quran Paper). Kelebihan metode MRP diantaranya kemampuan memberi harga lebih kompetitif, mengurangi harga penjualan, mengurangi inventori, pelayanan pelanggan yang lebih baik, Respon terhadap

permintaan pasar lebih baik, kemampuan mengubah jadwal induk, menunda atau membatalkan pesanan, mengubah kuantitas pesanan, memajukan atau menunda batas waktu pesanan. Kekurangan Metode MRP dipengaruhi oleh sistem integritas data. Jika terdapat data salah pada data persediaan, bill material data / master schedule kemudian juga akan menghasilkan data salah.

\section{Saran}

Beberapa saran dari penulis yang mungkin bisa menjadi masukan untuk perbaikan atau pertimbangan untuk perencanaan bahan baku di PT. Sygma Exa Grafika adalah:

1. Pada saat proses merencanakan kebutuhan bahan baku untuk produksi harus dilihat terlebih dahulu apakah stock di bagian gudang masih tersedia apa tidak.

2. Menjaga kondisi gudang penyimpanan terutama pada tingkat kelembababan dan tataletak gudang agar memperkecil kerusakan bahan baku terutama kertas QPP (Quran Paper).

3. Membuat sistem agar perencanaan penggunaan bahan baku lebih optimal lagi dan bisa meningkatkan produktifitas dalam pelaksanaan produksi.

4. Melakukan pelatihan-pelatihan SDM agar lebih menaati prosedur kerja dengan benar dan teliti.

\section{REFRENSI}

Hendra Kusuma. 1999. Manajemen Produksi Perencanaan dan Pengendalian Produksi. Yogyakarta : Andi

I Nyoman Yudha Astana, 2007. Jurnal Ilmiah Teknik Sipil. Denpasar. 
Vol. 6, No. 2, Oktober 2019, hal. 139-153

Mukhyidin Djaiz. 2010. Pengantar Ilmu Grafika. Jakarta.

Smile Magazine, edisi 14. 2015

Vincent Gaspersz,. 1998. Production Planning and Inventory Control
Berdasarkan Pendekatan Sistem Terintegrasi MRP II dan JIT Menuju Manufakturing 21. Jakarta : Gramedia Pustaka Utama 